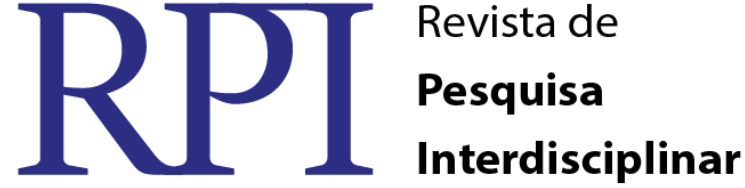

\section{GESTÃO ESCOLAR DEMOCRÁTICA E PARTICIPATIVA NA ESCOLA: ENTRE DESAFIOS E POSSIBILIDADES}

\author{
Mayrla Marla Lima Sarmento - CFP/UFCG \\ José Amiraldo Alves da Silva Alves - CFP/UFCG
}

\begin{abstract}
RESUMO
O trabalho tem como objeto de estudo a gestão escolar democrática e como questão de pesquisa as principais possibilidades e desafios enfrentados pela gestão escolar, no trabalho com a gestão de cunho democrático e participativo na escola. A partir desse delineamento, se definiu como objetivo geral, analisar as possibilidades e desafios do gestor em efetivar um trabalho de cunho democrático e participativo no âmbito escolar, e como objetivos específicos, identificar as dificuldades enfrentadas no trabalho com uma gestão escolar democrática e participativa; refletir a importância do Projeto Político Pedagógico da escola em relação ao trabalho da gestão escolar e averiguar a relação entre a existência de uma gestão democrática na escola e a qualidade das práticas que são desenvolvidas na instituição. A pesquisa teve um caráter exploratório, realizada por meio de uma abordagem qualitativa, com a utilização de observação e de questionário como instrumento de coleta de dados, constituído a partir de questões-tema. Participaram desse estudo a gestora e a coordenadora de uma instituição de ensino da cidade de Santa Cruz - PB. Os resultados apontaram que os desafios da gestão democrática estão ligados a questões como a pouca visibilidade da relevância da coletividade em prol das questões relativas à qualidade educativa da instituição, bem como que este tipo de gestão seja um instrumento que dê sustentação para as diferentes vivências, conflitos e desafios do âmbito escolar. Os resultados demonstraram também que existem possibilidades de exercício de uma gestão democrática, desde que sejam permeadas por um trabalho coletivo e que leve em consideração a diversidade de interesses dos sujeitos da instituição, como forma de democratizar os processos decisórios efetivados na escola.
\end{abstract}

Palavras-chave: Gestão. Democrática. Participativa. Desafios. Possibilidades.

\begin{abstract}
The work has as object of study the democratic school management and how the research question the main opportunities and challenges faced by the school management, working with the democratic and participatory nature management in school. From this design, defined as general objective to analyze the possibilities and challenges of the manager to effect a democratic nature of work and participatory in schools, and specific objectives, identify the difficulties in working with a democratic and participatory school management; reflect the importance of the school Pedagogical Political Project for the work of school management and to investigate the relationship between the existence of a democratic management in schools and the quality of the practices that are developed in the institution. The research had an exploratory character, accomplished through a qualitative approach, using observation and questionnaire as a data collection instrument, made from theme issues. Participated in this study the management and the coordinator of an educational institution in
\end{abstract}


the city of Santa Cruz - PB. The results showed that the challenges of democratic management are linked to issues such as poor visibility of the importance of the community in favor of issues related to educational quality of the institution and that this type of management is a tool that gives support to the different experiences, conflicts and challenges of the school environment. The results also showed that there are possibilities for exercise democratic management, provided they are permeated by a collective work and that takes into account the diversity of interests of the subjects of the institution as a way to democratize decision-making processes effected in the school.

Keywords: Management. Democratic. Participative. Challenges. Possibilities.

\section{INTRODUÇÃO}

O presente artigo é resultado de um estudo desenvolvido no curso de pós-graduação lato sensu em Planejamento e Gestão Escolar do Centro de Formação de Professores, na Universidade Federal de Campina Grande - campus de Cajazeiras, Paraíba. O interesse pela temática surgiu da inquietação em compreender as possibilidades e desafios enfrentados pelo gestor escolar, em efetivar uma gestão de cunho democrático e participativo na escola.

Para tanto, se definiu como objetivo geral, analisar as possibilidades e desafios do gestor em efetivar um trabalho de cunho democrático e participativo no âmbito escolar, e como objetivos específicos, identificar as dificuldades enfrentadas no trabalho com uma gestão escolar democrática e participativa na escola; refletir a importância do Projeto Político Pedagógico das escolas em relação ao trabalho da gestão escolar e averiguar a relação entre a existência de uma gestão democrática na escola e a qualidade das práticas desenvolvidas na instituição

A reflexão sobre a temática da gestão democrática e participativa torna-se relevante por ser uma necessidade emergente na realidade das escolas públicas e nos debates educacionais, no sentido de se promover transformações na educação que tem sido presenciada nos dias atuais.

Desse modo, a escolha da temática justifica-se diante da necessidade de que a sociedade contemporânea compreenda a relevância de se construir uma gestão democrática e participativa no âmbito das instituições de ensino, que envolva todos os seguimentos da comunidade escolar nesse processo.

RPI Revista de Pesquisa Interdisciplinar, Cajazeiras, v. 1, Ed. Especial, 286 - 296, set/dez. de 2016. 


\section{O Trabalho Da Gestão Democrática E Participativa Na Escola}

No Brasil, a administração da educação é vinculada aos princípios administrativos empresariais, devido a sua característica de sociedade capitalista, na qual os interesses do capital são presenças constantes nas metas e nos objetivos das organizações que devem se adequar ao formato impostos pela sociedade. Assim, o gestor escolar tem por função básica organizar e administrar, no sentido de que, "na sociedade dominada pelo capital, as regras capitalistas vigentes na estrutura econômica tendem a se propagar por toda a sociedade, perpassando as diversas instâncias do campo social” (PARO, 1990, p. 48).

A administração da educação, vista como um contíguo de decisões de interesse da vida escolar, precisa de uma nova aparência quanto a sua estruturação, no sentido de não se voltar para processos centralizadores, fragmentados, burocráticos que acabam por corroborar com o controle do capitalismo, e se abrir para decisões ancoradas na articulação dos interesses e das percepções dos vários segmentos sociais.

Por isso, a conquista da cidadania requer um esforço dos educadores em estimular instâncias e práticas de participação popular. A participação da comunidade possibilita o conhecimento, a avaliação dos serviços oferecidos e a intervenção organizada na vida da escola, podendo influenciar na democratização da gestão e na melhoria da qualidade de ensino (LIBÂNEO, 2001).

Esse movimento significou uma maior participação no que se refere às escolhas e caminhos consolidados para efetivação da proposta educacional das instituições de ensino, bem como das especificidades que são resultantes em prol de uma maior autonomia das escolas. Porém, a consolidação das lutas em defesa da participação de um maior número de pessoas nos processos decisórios que se faziam presentes no país em relação à educação, deuse no ano de 1996, com a criação da Lei de Diretrizes e Bases da Educação (LDB), n. 9394/96.

Parte dessas lutas acabou tendo como resultado, algumas discussões que contemplavam a organização do trabalho a ser desenvolvido pelas instituições de ensino no que se refere aos objetivos que devem estar presentes no Projeto Político Pedagógico da escola, como a referência para o alinhamento das ações coletivas a serem desenvolvidas na escola.

RPI Revista de Pesquisa Interdisciplinar, Cajazeiras, v. 1, Ed. Especial, 286 - 296, set/dez. de 2016. 
Para Libâneo (2001), dentre os eixos criados para melhor compreensão de como deveria se dar a organização do trabalho escolar nas instituições de ensino, encontram-se como principais norteadores desse trabalho, a flexibilidade, a responsabilidade, a autonomia, a participação e o planejamento coletivo. Todos esses aspectos são primordiais para a qualidade do trabalho que é desenvolvido nas instituições de ensino, a partir da elaboração e implementação do Projeto Político Pedagógico.

A autonomia por parte das instituições de ensino nos processos decisórios que competem a diferentes sujeitos presentes nesse espaço deve-se dar de forma espontânea e coletiva, de modo que a escola possa lidar com o oferecimento de práticas democráticas na instituição.

Para Freire (1999), a autonomia necessária às instituições de ensino nos processos decisórios, requer por parte de todos os envolvidos, um princípio de criatividade e de colaboração, para se consolidar diferentes caminhos que poderão ser trilhados pela instituição. Para tanto, o diálogo entre os sujeitos envolvidos nesse processo torna-se imprescindível na medida em que possibilita sua intervenção nas as ações que serão desenvolvidas nas instituições de ensino.

\section{Principais desafios e dificuldades de implementação da gestão democrática e participativa na escola}

A consolidação de uma gestão democrática na escola não ocorre de forma automática ou espontânea. A dinâmica das relações de poder interfere no avanço do processo, sendo preciso um esforço coletivo e direcionado para as decisões coletivas, que superem os interesses individuais.

Segundo Paro (1990), a gestão democrática da educação requer mais do que mudanças simples, precisa de uma mudança de paradigmas que sustentam a construção de uma proposta educacional e o desenvolvimento de uma gestão distinta da que é praticada nos dias de hoje em muitas instituições. Ela necessita estar além dos padrões vigentes, que são desenvolvidos pelas organizações burocratizadas.

O intuito é que toda a prática seja consolidada através de ações embasadas na parceria dos sujeitos no interior da escola, bem como da instituição escolar com a família e a RPI Revista de Pesquisa Interdisciplinar, Cajazeiras, v. 1, Ed. Especial, 286 - 296, set/dez. de 2016. 
comunidade como um todo, visando realizar princípios e missão adotados pela escola, dentro de uma atuação de prudência, porque "o PPP é a própria organização do trabalho pedagógico da escola" (VEIGA, 2004, p. 22).

No que diz respeito à participação dos docentes e da gestão nesse processo, a LDB estabelece que:

Art. $13^{\circ}$. Os docentes incumbir-se-ão de:

I - participar da elaboração da proposta pedagógica do estabelecimento de ensino;

II - elaborar e cumprir plano de trabalho, segundo a proposta pedagógica do estabelecimento de ensino;

No artigo $14^{\circ}$ ressalta que:

Art. $14^{\circ}$. Os sistemas de ensino definirão as normas da gestão democrática do ensino público na educação básica, de acordo com as suas peculiaridades e conforme os seguintes princípios:

I - participação dos profissionais da educação na elaboração do projeto pedagógico da escola (BRASIL, 1996).

Compreende-se a partir do exposto, que a Lei garante a relevância da participação significativa de professores das diferentes áreas, bem como da gestão escolar nos processos decisórios que perpassam o âmago das instituições de ensino. Deste modo, a referida Lei ainda enfatiza a participação na elaboração, no cumprimento diário dos planos e metas apontados no projeto implementado na instituição. A qualidade da construção final do projeto será resultado e reflexo da atuação ativa de uma instituição pautada em um trabalho de gestão democrática.

Porém, a gestão da maioria das escolas nos processos de elaboração e implementação de práticas democráticas nos diferentes espaços, vivencia dificuldades, e uma delas diz respeito à pouca participação efetiva dos demais profissionais, no trabalho coletivo com a gestão escolar.

Desta maneira, se parte do entendimento de que a gestão democrática é uma necessidade, e que para existir deve haver diálogo entre funcionários, professores, gestores, alunos e familiares, enfim, todos aqueles que participam da instituição escolar, no sentido de que se possam estabelecer parâmetros para a melhor execução do trabalho pedagógico na escola.

RPI Revista de Pesquisa Interdisciplinar, Cajazeiras, v. 1, Ed. Especial, 286 - 296, set/dez. de 2016. 


\section{Delineamento Dos Aspectos Metodológicos Da Pesquisa}

Os procedimentos de pesquisa são construtos relevantes para um melhor conhecimento da realidade de determinada investigação. Entretanto, iniciar uma pesquisa em qualquer tipo de instituição, em princípio pode surgir algumas inseguranças, dificuldades e desconfianças por parte dos sujeitos investigados.

No estudo se adotou uma abordagem qualitativa, pois segundo Oliveira (2008), há uma relação recíproca e interdependente entre sujeito e objeto, de modo que espera-se do pesquisador uma posição de reflexão e de análise diante da realidade do que se deseja pesquisar, utilizando-se de técnicas que possibilitam uma visão mais detalhada e clara do seu objeto.

No processo de pesquisa, inicialmente, foi feito um levantamento bibliográfico sobre a problemática estudada. Em seguida, realizou-se uma pesquisa de campo do tipo exploratória em torno do objeto, adotando técnicas de pesquisa que possibilitassem a coleta de dados, para posterior análise.

Outro aspecto a ser destacado em uma pesquisa é a caracterização do lócus da pesquisa e dos sujeitos envolvidos para a efetivação do trabalho, de modo que participaram dessa investigação, uma gestora e uma coordenadora de uma escola pública da rede estadual de ensino da cidade de Santa Cruz - PB.

Os dados da pesquisa foram coletados através da observação e aplicação de um questionário contendo algumas questões-temas, na qual a pesquisadora teve total abertura para interagir com o sujeito da pesquisa, de modo a tornar a coleta de dados mais significativa e relevante para os objetivos almejados alcançar.

Nesse sentido, a observação e o questionário foram escolhidos para coleta de dados para a realização dessa pesquisa. Visto que, a utilização dessa técnica apresenta uma serie de vantagens, bem como é descrito no pensamento da autora Lakatos (2003, p.201):

A escolha de técnica de questionários semi-estruturados possibilita ao entrevistador economização de tempo, grande número de dados, maior número de pessoas, respostas mais rápidas e mais precisas, maior liberdade nas respostas em razão do anonimato dos pesquisados, mais segurança pelo fato das respostas não serem identificadas, menos riscos de distorção pela não influência do pesquisador, mais tempo para responder e em hora mais favorável, mais uniformidade na avaliação.

RPI Revista de Pesquisa Interdisciplinar, Cajazeiras, v. 1, Ed. Especial, 286 - 296, set/dez. de 2016. 
A adoção de questionários propicia uma série de vantagens ao pesquisador, e foi a partir desses critérios que se deu a utilização dessa técnica de investigação. Nesse sentido, foi adotado o uso de questionário composto por tópicos constituídos por uma série ordenada de perguntas, que foi respondida pelas participantes por escrito. Para a análise dos dados coletados com aplicação do questionário, foi tomada como base de sustentação a análise dos principais desafios e possibilidades no processo de elaboração do PPP.

\section{Análise Dos Dados}

No período de observação realizado durante o planejamento semanal da escola lócus dessa pesquisa, percebeu-se que no que diz respeito à forma como ocorre o planejamento, que este se apresenta de forma participativa, onde todos interagem e discutem as principais dificuldades dos alunos, bem como planejam as aulas para semana, buscando sempre inovar as atividades.

A coordenadora sempre está motivando as professoras e buscando saber como estão os alunos em sala, vendo se as atividades estão de acordo com a idade/ano. Já a gestora participa do planejamento para repassar algumas informações da gerência de ensino, bem como outras questões que se façam necessárias nesse espaço.

Dentre os principais desafios que as profissionais enfrentam na instituição, demonstrados nas conversas durante o planejamento, se tratam do trabalho com as crianças com deficiências, pelo qual as professoras relataram as dificuldades de trabalharem certas atividades com tais crianças em sala de aula junto aos demais alunos.

Já no que diz respeito à aplicação do questionário, este foi respondido pela coordenadora e pela gestora da instituição no lócus da pesquisa, de modo que trazemos aqui uma análise geral das questões abordadas com ambas as profissionais.

Em relação ao modo como acontece o processo de tomada de decisões na instituição em que as profissionais trabalham, estas nos disseram que:

Bom, a questão escolar não pode ser encerrada somente como um conjunto de práticas burocráticas voltadas a escola na maioria dos casos, mas sim precisa ser vista como um viés de promover e acontecer a democracia da comunidade, família e escola nem só ângulo, onde vise proporcionar êxito na educação (COORDENADORA). 
Em uma organização coletiva, como a escola existe várias dimensões que requerem decisões, seja na parte administrativa, pedagógica, financeira ou organizacional (GESTORA).

Pode-se observar nas falas das profissionais, que estas compreendem a necessidade de um processo de tomada de decisões que abarque a participação de toda a comunidade escolar, de modo que se possa levar em consideração as opiniões e posicionamentos de uma diversidade de sujeitos a respeito de diferentes questões que são pertinentes ao cotidiano da instituição de ensino. Outro aspecto relevante é na fala da gestora, quando relata a necessidade de estarmos atentos, durante os processos de tomada de decisões, com que é posto em relação à missão e os objetivos do Projeto Político Pedagógico.

A gestora tem conhecimento acerca da relevância do Projeto Político Pedagógico numa instituição de ensino, na medida em que suas ações devem estar condizentes com as necessidades do público atendido nos diferentes contextos, pois, é a partir do conhecimento das particularidades do público alvo, que a gestão juntamente com os demais profissionais que dela fazem parte, poderá agir mediante pontos específicos a serem analisados e melhorados no âmbito escolar.

No que diz respeito à relação entre a existência de uma gestão democrática na escola e a qualidade das práticas que são desenvolvidas na instituição, as participantes da pesquisa disseram que:

Compreendo que a gestão democrática pode ser considerada como meio pelo qual todos os segmentos que compõem o processo, educativo participam da definição dos rumos que a escola deve tomar à educação de maneira a efetivar essas decisões num processo continuo de avaliação de suas ações e refletir as práticas se está havendo a efetiva democratização (COORDENADORA).

A gestão democrática promove engajamento, envolvimento entre todos os segmentos da comunidade escolar nas decisões, as ações da gestão se tornam mais transparente, participativa, e principalmente, são corresponsáveis pelos processos e resultados obtidos no processo de ensino e aprendizagem respeitando, as funções principais de cada segmento (GESTORA).

A qualidade das práticas que são efetivadas em qualquer instituição de ensino, de uma forma ou de outra está relacionada com o tipo de gestão que é implementada nesse espaço, de modo que tal proposta reflete no direcionamento das ações pensadas e efetivadas nesse RPI Revista de Pesquisa Interdisciplinar, Cajazeiras, v. 1, Ed. Especial, 286 - 296, set/dez. de 2016. 
processo.

Como se pode percebe na resposta das profissionais quando dizem que a gestão democrática promove o engajamento de uma série de profissionais, e desse modo, promove também a qualidade das práticas que são desenvolvidas nesse espaço, pois possibilita um olhar de diferentes sujeitos e contextos para com as particularidades do cotidiano escolar (PARO, 2006)

Já no que concerne as possibilidades de democratização a gestão na escola, ou seja, no que diz respeito aos meios mais viáveis que envolvam os sujeitos da comunidade escolar nesse processo, a gestora relatou que:

Os meios até o momento para promover esta participação dos sujeitos envolvidos, é através da convocação para reuniões, visitas na escola, incentivo aos alunos para que seus pais venham até a escola, participem, conversem, acompanhem, procurem a professora, coordenação pedagógica, gestão escolar (GESTORA).

A gestão busca meios para ampliar a participação de outros sujeitos fora da escola nos processos de tomada de decisão de diferentes aspectos que concerne o cenário escolar como um todo, de modo que realiza essa abertura através dos encontros periódicos organizados pela instituição, com o intuito de aproximar pais, responsáveis, alunos e demais profissionais da escola, como forma de atribuir maiores elos entre tais sujeitos em prol da qualidade das práticas que são realizadas no âmbito escolar.

A escola pautada em um trabalho que viabilize a materialização de uma gestão democrática nas suas práticas, firma um compromisso de realizar a partir de uma elaboração coletiva, que leve em consideração os principais problemas e necessidades particulares de diferentes grupos. Para isso, é necessária a superação das dicotomias existentes entre teoria e prática, entre processos de concepção e execução de propostas.

\section{Conclusão}

Compreende-se que este momento de conclusão, a partir do que foi coletado e analisado na pesquisa de campo originária da investigação para este artigo, é uma reflexão acerca do que foi coletado mediante o objeto de estudo, pois, na medida em que lêem-se os 
dados, percebe-se tantas outras possibilidades de se efetivar estudos e pesquisas acerca da temática, a partir da existência de um determinado objeto e problema de pesquisa a ser investigado.

Desse modo, a questão-problema desse estudo foi compreender as principais possibilidades e desafios enfrentados pelo gestor escolar no tocante ao trabalho com uma gestão de cunho democrático e participativo na escola. Considera-se que a questão foi respondida, na medida em que foi possível compreender que essas possibilidades são muitas, sendo que tendem a ser permeadas por um trabalho coletivo e levando em consideração a diversidade de interesses dos sujeitos da instituição, como forma de democratizar os processos decisórios efetivados na escola.

Já os desafios estão ligados a diferentes situações como a falta de participação dos professores, pouca visibilidade da relevância da coletividade em prol das questões relativas à qualidade educativa da instituição, além da possibilidade desse tipo de gestão ser um instrumento que dê sustentação para as diferentes vivências, conflitos e desafios no âmbito escolar.

Nessa perspectiva, compreende-se que é necessário cada vez mais resgatar os espaços de debate e diálogo no contexto das instituições, ao ponto que esse é um caminho para se chegar a uma reflexão coletiva das ações educativas.

Para tanto, os processos de construção, execução e avaliação do Projeto Político Pedagógico nas escolas públicas, devem levar em consideração as continuidades das ações realizadas a partir de uma perspectiva de gestão democrática e participação coletiva de todos os profissionais. A própria reorganização da instituição, necessita da construção de um projeto que esteja condizente com a realidade do público atendido, bem como de sugestões para melhoria do desempenho da instituição.

\section{REFERÊNCIAS}

BRASIL. Constituição Federal de 1988. Promulgada em 5 de outubro de 1988.

Senado Federal. Lei de Diretrizes e Bases da Educação Nacional: nº 9394/96.

Brasília: 1996.

RPI Revista de Pesquisa Interdisciplinar, Cajazeiras, v. 1, Ed. Especial, 286 - 296, set/dez. de 2016. 
FREIRE, P. Pedagogia da autonomia: saberes necessários à prática educativa. São Paulo: Paz e Terra, 1999.

LAKATOS, E. M. Fundamentos de metodologia científica. 5. ed. - São Paulo: Atlas, 2003.

LIBÂNEO, José Carlos. Organização e gestão da escola: teoria e prática. Goiânia: Alternativa, 2001.

PARO, V. H. Gestão democrática da escola pública. 3. ed. São Paulo: Ática, 2006.

OLIVEIRA, M. M. de. Como fazer pesquisa qualitativa. 2 ed. Petrópolis, RJ: Vozes, 2008.

VEIGA, I. P. A. (Org.). Projeto político-pedagógico da escola: uma construção possível. Campinas-SP: Papirus, 2004. 